\title{
Sobre el amor y el fervor. Música, piedad y corte en los reinos hispanos medievales
}

\author{
Arturo Tello RuIZ-PÉREZ \\ Universidad Complutense de Madrid \\ Departamento de Musicología \\ atelloru@ghis.ucm.es
}

\section{RESUMEN}

Con el ánimo de indagar en las causas para entender los efectos, al menos como premisa, este trabajo plantea unas breves reflexiones sobre cuáles son los parámetros más o menos constantes en los repertorios musicales de los reinos hispanos medievales. De esta manera, el amor (también el fervor) es tomado como auténtica fuerza generadora y guía de la creatividad, con especial incidencia a partir del s. XII. Algunos ejemplos significativos y paradigmáticos, por tanto, son tomados para ilustrar algunas maneras y contextos en los que esto se produce.

Palabras clave: Música medieval, canción litúrgica, trovadores, amor en la Edad Media, repertorios hispanos, Peire Vida, Códice Calixtino, Códice de Las Huelgas.

\section{About Love and Fervour. Music, Piety and Court in the Late Middle Ages Kingdoms of Hispania}

\begin{abstract}
With the aim of investigate the causes to understand the effects, at least as a premise, this paper presents some short reflections on what parameters are more or less constant in the musical repertoire of medieval Hispanic kingdoms. Thus, love (also the fervour) is taken as authentic driving force and guide of creativity, with special emphasis since the twelfth century. Some significant and paradigmatic examples are taken to show some ways and contexts in which this occurs.
\end{abstract}

Key words: Medieval music, liturgical song, troubadours, love in the Middle Ages, hispanic repertoires, Peire Vidal, Calixtinus Codex, Las Huelgas Codex. 
Pudiera parecer cosa extraña para el título de una aportación científica este reunir en asamblea conceptos, en principio, de índole diversa: amor, música, fervor, corte, piedad, reino. Ciertamente lo es; no nos vamos a engañar. Pero hay momentos en los que enfrascarse en la emoción de una aventura, acaso una travesura, bien encierra en tanto que experimento -valga que la palabra comparte derivación con experiencia-algo de lo que es costumbre que al frío microscopio de la crítica se le suele escapar en pos del detalle. Y es que una veneración excesiva por la parte a veces conmina sin remedio, aun sin mala intención - todo lo contrario-, a la razón del ser general de las cosas, a su desenvolverse primigenio y germinal. Cuando un problema o una cuestión particular se enclaustran sobre sí, se proponen como un fin último, con frecuencia se apartan del desbordamiento al que su propia naturaleza les impele, perdiéndose todo o parte de la comprensibilidad emanada de aquellos veneros más elevados y causales que les dan el sentido. Por ejemplo, el operario que desmonta las piezas de un mecanismo, mientras las tiene en sus manos, bajo su mirada, si realmente quiere comprenderlas, no puede obviar en su pensamiento el lugar y función que ocupan en el conjunto. Así nosotros: el objeto, entonces, puede determinar el método, por supuesto, pero no el espíritu.

In promptu que no se trata aquí, por tanto, de poner en liza o parangón lentes y perspectivas posibles en la aproximación científica, pues todas guardan a partes iguales tantas virtudes como defectos. Nuestra intención, más bien, se entrevera en el trasladar la atención hacia el espíritu que descansó en buena parte de la producción de objetos musicales de sobre todo del s. XII en adelante, y partir de él, para resituar algunos de estos en la justa medida del conjunto donde se desenvolvieron, actuaron y recibieron acción, donde implantaron sus condiciones al tiempo que recibieron otras. Pero ¿por qué algunos objetos, tomados no más que como muestras ejemplares de un hacer y de un querer, si lo que pretendemos es anclarnos en el espíritu de la causa? La respuesta, de forma tan concisa como hermosa, la apunta Santo Tomás de Aquino como el primero de sus consejos al estudiante Juan: "Ut per rivulos, non statim, in mare eligas introire: quia per faciliora ad difficiliora opportet devenire" ${ }^{\text {[Escoge }}$ entrar en el mar no de golpe, sino a través de los riachuelos; ya que es a través de lo más fácil que conviene llegar a lo más difícil]. Por consiguiente, nuestros riachuelos, los objetos individuales que trataremos, no poseen un valor absoluto per se capaz de valer como norma, ya que son conductores, toda vez que este valor sí lo posee el mar general del espíritu en el que desembocan y que, en virtud de un peculiar ciclo del agua, ya había estado también en los remansos de su nacimiento. Parece evidente: lo sencillo no necesita método; en cambio, lo complicado necesita un método sencillo.

En esta visión rapaz -por cuanto breve- acerca de la música en los reinos hispanos medievales, demos paso ahora a dar nombre a ese espíritu generador y generalizador al que estamos aludiendo. Es decir, vayamos a la levadura que, como fons et origo, ha de fermentar todo nuestro discurso a razón de ser verdadero nutriente de repertorios: el amor, siempre el amor, no se trata de otra cosa. Sin embargo, dada la ingente cantidad de posibilidades y de literatura, conviene tomar un punto de arranque lo

1 A.D. SERTILLANGES, Prières de Saint Thomas d'Aquin, Paris, 1920, p. 104. Salvo indicación, todas las traducciones son mías. 
suficientemente seguro y aclaratorio para ello. Cuál mejor que esa síntesis de toda síntesis de la Edad Media que supone la Commedia y el último e inmortal verso del Paradiso de Dante: "l'amor che move il sole e l'altre stelle"2 [el amor que mueve el sol y las otras estrellas].

Aquí confluyen muchas cosas, naturalmente, pero entre las más importantes ahora mismo para nosotros destacan sobre todo dos: de forma explícita, que el amor lo circunda todo y todo lo abraza; de manera más implícita, que el amor es ante todo deseo. No es baladí que Dante escoja precisamente la palabra stelle para concluir el Inferno ${ }^{3}$ y el Purgatorio ${ }^{4}$ puesto que ésta permanece clavada en la composición misma del término "deseo": de-sidus (de-sidera) / de-siderare, es decir, de las estrellas o, en cierto modo, un qué tiene que ver cada uno con las estrellas, con el infinito. Es así que, en suma, Dante vendría a advertir maravillado, a guisa de colofón, sobre la permeabilidad del cosmos entero a una única ley, la del deseo, movida y ejecutada por la fuerza eternal del amor.

De esta manera, puede decirse que la dualidad amor-deseo yace en los cimientos del pensamiento occidental. Baste sólo tomar como dos de sus ejes fundadores el Cantar de los Cantares bíblico y el Banquete platónico, algo que resultará de lo más necesario, a más de provechoso, para nuestro propósito de mostrar este foco generador compositivo durante la Edad Media. En el Cantar de los Cantares, el amado se arrasa enfervorizado de elogios hacia la amada:

¡Qué bella eres, qué encantadora, oh amor, oh delicias!

Tu talle se parece a la palmera, tus pechos, a los racimos.

Me dije: Subiré a la palmera, recogeré sus frutos. ¡Sean tus pechos como racimos de uvas, el perfume de tu aliento como el de las manzanas,

tu paladar como vino generoso! [Cant. 7, 7-10]

Y la amada no duda en responder:

Yo soy para mi amado, y hacia mí tiende su deseo.

¡Oh, ven, amado mío, salgamos al campo! Pasaremos la noche en las aldeas.

De mañana iremos a las viñas; veremos si la vid está en cierne, si las yemas se abren, y si florecen los granados. Allí te entregaré el don de mis amores. [Cant. 7, 11-13]

Por su lado, Platón, a través de Aristófanes, después de identificar en el alma el despertar vivo del recuerdo de una preterición originaria que ansía su lugar de retorno en la conciencia, afirma que "amor es, en consecuencia, el nombre para el

2 Paradiso 33, 145. DANTE ALIGHIERI, La Commedia secondo l'antica vulgata, G. PETROCCHI (ed.), Milán, 1966-67, vol. 4, p. 558.

3 "E quindi uscimmo a riveder le stelle" [Y después salimos para volver a ver las estrellas]. Inferno 34, 139. DANTE ALIGHIERI, op. cit., 1966-67, vol. 2, p. 598.

4 "Puro e disposto a salire a le stelle" [Puro y dispuesto para ascender a las estrellas]. Purgatorio 33, 145. DANTE ALIGHIERI, op. cit., 1966-67, vol. 3, p. 585. 
deseo y persecución de esta integridad". 5 Pero en este deseo, puntualiza Diotima a Sócrates, debe haber ante todo una búsqueda de lo bueno:

Y se cuenta, ciertamente, una leyenda, según la cual los que busquen la mitad de sí mismos son los que están enamorados, pero, según mi propia teoría, el amor no lo es ni de una mitad ni de un todo, a no ser que sea, amigo mío, realmente bueno, ya que los hombres están dispuestos a amputarse sus propios pies y manos, si les parece que esas partes de sí mismos son malas. Pues no es, creo yo, a lo suyo propio a lo que cada cual se aferra, excepto si se identifica lo bueno con lo particular y propio de uno mismo y lo malo, en cambio, con lo ajeno. Así que, en verdad, lo que los hombres aman no es otra cosa que el bien. ¿O a ti te parece que aman otra cosa? ${ }^{6}$

La sentencia que viene poco después es sumamente elocuente en lo que al deseo se refiere: "Entonces -dijo-, el amor es, en resumen, el deseo de poseer siempre el bien". 7

De juro que ambos testimonios hacen referencia al deseo como encarnación del amor, como su constancia y consistencia, pero inmediatamente salta la diferencia

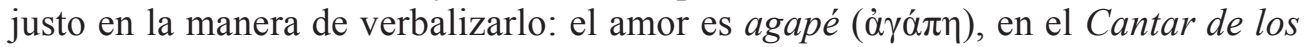

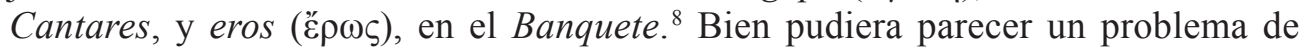
simple terminología de no encerrar una fundamentación más profunda de orden existencial frente a la realidad. No en vano detrás se hallan, por un lado, la visión hebrea del mundo, en la que el hombre sabe bien -o sabría si se lo propusiera- lo que es razonable, de modo que si no lo hace es por pura perfidia; y, por otro, la visión griega, en virtud de la cual el hombre haría siempre aquello que fuera razonable si lo supiera, si tuviera los datos correctos o si extrajera conclusiones seguras de lo que sabe. ${ }^{9}$ En la perspectiva hebrea prima la voluntad, en la griega, la mente, el intelecto.

El eros platónico, entonces, es una fuerza quasi divina de arrobamiento del ser humano, algo que lo sitúa en un más allá de los límites de su existencia e introduce un augurio de cumplimiento, de infinitud y de eternidad. Se impone a la razón, y de ahí que deba ser antes de nada la búsqueda del bien porque, de no ser así, puede conducir hacia un extravío ciego y devastador. No obviemos que, en el Banquete, el juicio sobre el mejor discurso acerca de eros debe emitirlo en última instancia Dioniso. Consiguientemente el hombre, en tanto que símbolo ( $\sigma u ́ \mu \beta o \lambda o v),{ }^{10}$ tiene en potestad el apego hacia el deseo amoroso como percepción de correspondencia

\footnotetext{
5 Banquete, cols. 192e-193a. PLATÓN, Diálogos III. Fedón, Banquete y Fedro, C. GARCÍA GUAL, M. MARTÍNEZ HERNÁNDEZ y E. LLEDÓ ÍÑIGO (trads.), Madrid, 1988, p. 228.

6 Banquete, cols. 205d-206a. PLATÓN, op. cit., 1988, p. 253.

7 Banquete, col. 206b. PLATÓN, op. cit., 1988, p. 254.

8 Remitimos en ambos casos a las versiones griegas de las citas aducidas en A. RAHLFS (ed.), Septuaginta, Stuttgart, 1935, vol. 2 y J. BURNET (ed.): Platonis opera. Recognovit brevique adnotatione critica instruxit, Oxford, 1900-1907, vol. 2.

9 Véase para un mayor razonamiento sobre este tema A. MURRAY, Razón y sociedad en la Edad Media, J. FERNÁNDEZ BERNALDO DE QUIRÓS (trad.), Madrid, 1982, pp. 13-17.

10 Banquete, col. 191d. PLATÓN, op. cit. 1988
} 
en un impulso de "locura" dirigente hacia lo divino $\left(\theta \varepsilon i \tilde{\alpha} \mu \alpha v^{\prime} \alpha\right),{ }^{11}$ hacia el ideal de belleza de la unidad perdida. Pero esta búsqueda está abocada a los caprichos de la casualidad dado que:

nuestra mitad se halla en alguna parte, pero es difícil utilizar la razón y la planificación para encontrarla. Las criaturas "buscan" y "se reúnen", pero es obvio que no está en su mano garantizar la venturosa unión. Cuesta aceptar que algo tan esencial para nuestro bien como es el amor dependa del azar hasta este punto. ${ }^{12}$

La insuficiencia, la carencia y la infelicidad se instalan como ordinarios en la vorágine del deseo humano, y aquí reside, en el no ver colmada la aspiración por la

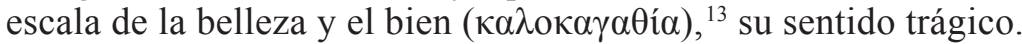

Aunque es cierto que la Edad Media europea no conoce de primera mano el Banquete y otros diálogos hasta muy tarde, el pensamiento platónico sobre el eros queda diseminado a través principalmente de los poetas y retóricos romanos, como Cicerón, Plotino y Porfirio, traducidos al latín por Mario Victorino en el s. IV; de los Padres de la Iglesia, sobresaliendo entre ellos San Agustín de Hipona; o de Boecio. ${ }^{14}$ Tampoco puede desdeñarse el hilo de los círculos de influencia del amor $u d r i$ celebrado por los cantores sufíes de Al-Ándalus. En cualquier caso, algo relevante para nuestra exposición es la filtración de la noción de que la música, la harmonia

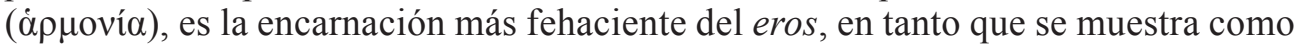
un puente entre el mundo de las ideas y el de los fenómenos.

Así, la veta platónica llega hasta la primera gran formulación doctrinaria del amor desarrollado en las cortes por parte de André le Chapelain, eso sí, en mezcolanza con un claro prisma ovidiano:
"Amor est passio quaedam innata procedens ex visione et immoderata cogitatione formae alterius sexus, ob quam aliquis super omnia cupit alterius potiri amplexibus et omnia de utriusque voluntate in ipsius amplexu amoris praecepta compleri." 15
[El amor es cierta pasión innata que procede de la visión y de la meditación exce- siva sobre la belleza del otro sexo, que hace que cada uno desee, por encima de todas las cosas, los abrazos del otro y cumplir, de mutua voluntad, todos los preceptos del amor en su abrazo].

El amor es un sufrimiento innato, un deseo que manifiesta la incapacidad humana de plenitud transida por la exigencia de belleza y de bondad, "quia semper timet amans ne amor optatum capere non possit effectum, nec in vanum suos labores

\footnotetext{
11 Fedro, col. 265a-c. PLATÓN, op. cit., 1988

12 M.C. NUSSBAUM, La fragilidad del bien: fortuna y ética en la tragedia y la filosofia griega, A. BALLESTEROS (trad.), Madrid, 1995, p. 241.

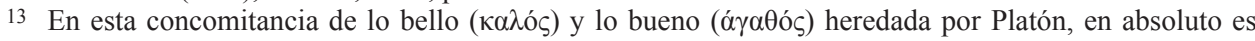

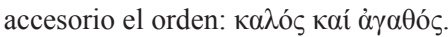

14 Véanse R. KLIBANSKY: The Continuity of the Platonic Tradition During the Middle Ages: Outlines of a Corpus Platonicum, Londres, 1939, pp. 22-24 y 27-29; y N. E. VAN DEUSEN: The Harp and the Soul: Essays in Medieval Music, Lewiston, 1989, pp. 386 y 408, notas. 8-10.

15 E. TROJEL (ed.), Andreae Capellani regii Francorum de Amore libri tres, Copenhague, 1892, p. 3.
} 
emittat" ${ }^{16}$ [porque siempre teme el amante que su amor no tenga el efecto deseado y que sus esfuerzos sean en vano]. Pero derogando en parte la dimensión metafísica translúcida de un planteamiento platónico -ahí esté probablemente Ovidio-que, al fin y al cabo, siempre permanece inscrito como ideal en la órbita del alma, André asume como razonable la atracción desiderativa por el objeto amado con un evidente sesgo sexual. Ovidio, y por qué no también Lucrecio, se corporeizan en este sentido en pasajes tan significativos como:

"Nam quum aliquis videt aliquam aptam amori et suo formatam arbitrio, statim eam incipit concupiscere corde; postea vero quotiens de ipsa cogitat, totiens eius magis ardescit amore, quousque ad cogitationem devenerit pleniorem. Postmodum mulieris incipit cogitare facturas, et eius distinguere membra suosque actus imaginari eiusque corporis secreta rimari ac cuiusque membri officio desiderat perpotiri. "17

[Ya que cuando uno ve a alguna mujer apta para el amor y formada según su gusto, de inmediato empieza a desearla en su corazón; a continuación, cuanto más piensa en ella tanto más que arde su amor, hasta que llega a una reflexión más detallada. En seguida comienza a meditar en la forma de la mujer y a distinguir sus miembros, a imaginar sus actos y a escudriñar los secretos de su cuerpo, y desea disfrutar plenamente del favor de cada parte].

El idealismo y el naturalismo del eros se vierten en la tinaja del s. XII para dar lugar a una cultura amorosa, la de las cortes, en la que conviven, por supuesto en gradaciones diferentes, los elementos metafísicos del alma con los apetitos sensibles del cuerpo. Por eso creo que no se puede decir que la fin'amor, expresión máxima de este sentimiento para los trovadores, sea de raigambre platónica, aunque lo platónico se erija como parámetro esencial, ni que mucho menos sea un abandono a la querencia instintiva del sexo, a pesar de que en ocasiones así ocurra. Se trata en realidad del amor afinado, depurado, como la fundición del oro en la craza, donde se excoria toda impureza; un amor con firme voluntad de separarse de toda bajeza villana. Incluso en los casos más carnales es así, aunque parezca mentira, quizá -y en ello comparto la opinión de Lewis- porque Ovidio fuera tomado demasiado en serio. ${ }^{18}$ Desde el principio -ahí está Guilhem de Peitieu-, ni es demasiado difícil encontrar ejemplos donde el objeto amado aparece idealizado e inaccesible, ni otros, e incluso dentro de otros, donde es el naturalismo, a veces repleto de concupiscencia, el que toma las riendas.

No hay una propuesta teórica coherente de la fin 'amor -eso es lo que tratarían de hacer André le Chapelain o Matfre Ermengau-, así como tampoco una voluntad de que así fuera. Más bien existen salpicaduras en forma de afirmaciones apasionadas y palinodias, de anuncios y renuncios que, de canto en canto, de vez en vez, operan la mudanza del concepto en un crisol de mil colores y variaciones. Ahora bien, si definiéramos la fin'amor como un sistema sanguíneo, en él detectaríamos de inme-

16 TROJEL (ed.), op. cit., p. 3.

17 E. TROJEL (ed.), op. cit., 1892, p. 5.

18 C.S. LEWIS, La alegoría del amor. Un estudio sobre tradición medieval, B. FERNÁNDEZ BIGGS (trad.), Santiago de Chile, 2000, pp. 14-16. 
diato dos circuitos, uno arterial, por donde sale la sangre idealizada del corazón, y otro venoso, por medio del cual ésta retorna carnalmente al mismo. Antojos del lenguaje, pareciera incluso haber una relación entre vena y Venus: ambos términos derivan de venire, venir. De cualquier modo, sea por la arteria del alejado e inaccesible idealismo o por la vena de la cercana sensualidad, la fin'amor se muestra como una depuración del deseo similar a la harina cernida que sale de un cedazo espeso. Porque el deseo fermenta toda manifestación nacida de esta díada de eros y, sin solución de continuidad, ello conduce a uno de los hitos fundamentales dentro de este alumbramiento de intimidad entre amor y poesía articulado por los trovadores: su sino paradójico.

Reducida a su mínima expresión, la paradoja consiste en que si el amor (eros) es deseo, el deseo busca siempre verse colmado de modo que, toda vez que encuentra satisfacción, inevitablemente fenece, desaparece. Está en la entidad del deseo, por tanto, anhelar su muerte. Prefiere el deceso a la vida, y si decide vivir debe hacerlo necesariamente desde la insatisfacción y el no cumplimiento.

Momento ahora es de presentar el primero de nuestros casos (Ejemplo 1), enraizado en esta idiosincrasia nacida de la fin'amor. Se trata de Baron de mon dan covit, una cansó, a medio camino con el gap, del tolosano Peire Vidal, cuya actividad puede ser fechada con seguridad entre 1180-1204. Esta cansó, con tintes de balandronada y que desemboca en un dictamen moral sobre el daño de los maldicientes, puede ser fechada ante quem en 1192, año en el que muere Barral, vizconde de Marsella y mentado en la cobla IV.

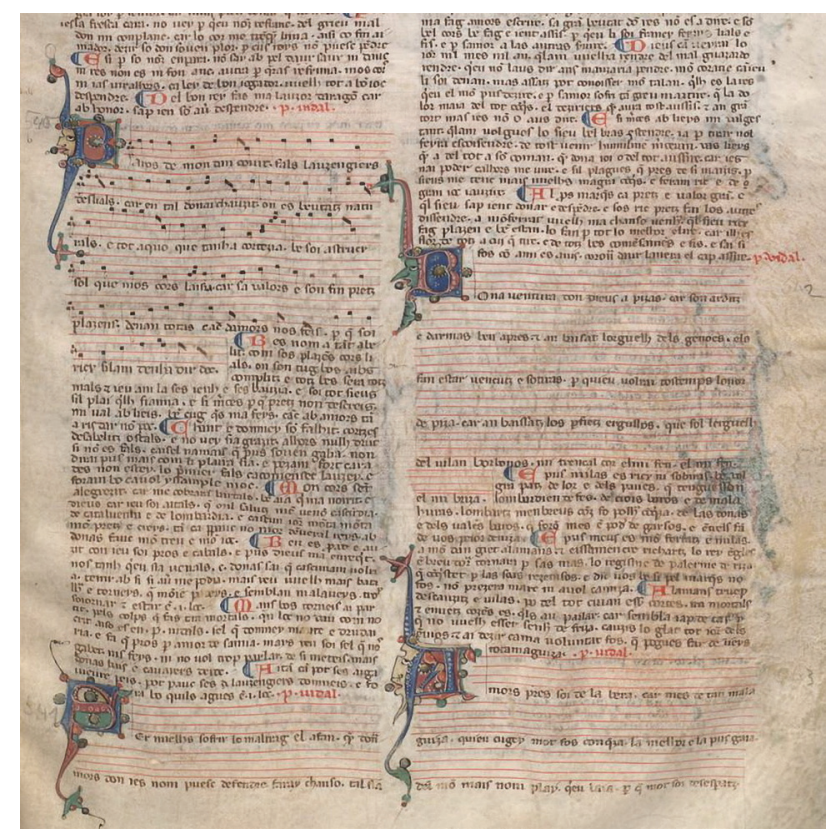

Fig. 1. Baron de mon dan covit. París, Bibl. Nat., fr. 22543, f. 65r (s. XIV). 


\section{Ejemplo 1. Texto y traducción de Baron de mon dan covit de Peire Vidal ${ }^{19}$}

I. Baron, de mon dan covit

fa 1 lauzengiers deslials, qu'en tal domna ai chauzit, ont es fis pretz naturals.

Et ieu am la de cor e ses bauzia et sui totz sieus, quora qu'ilh sia mia, qu'a sa beutat e sa valor pareis, qu'en lieis amar honratz fora us reis, per que $\cdot \mathrm{m}$ tieng ric sol que $\cdot \mathrm{m}$ deinh dire d'oc.

II. Anc res tan no m'abellit cum sos adreitz cors lials, on son tug bon aip complit e totz bes sense totz mals. E pus tot a quan tainh a drudaria, ben sui astrucs, sol que mos cors lai sia; e si merces, per que totz bos aips creis, mi val ab lieis, be us puesc dir ses totz neis, qu'anc ab amor tant ajudar no $\mathrm{m}$ poc.

III. Chant e solatz vei fallit, cortz e dous e bos hostals, e domnei no vei grazitm si $\cdot$ lh domn'e 1 drutz non es fals.

Aquel n'a mai que plus soven galia.

No $n$ dirai plus, mas cum si vuelha sia.

Mas peza me quar ades non esteis

le premiers fals que comenset anceis:

e fora dreitz, qu'avol eixample moc.

IV. Mon cor sent alegrezit, quar me cobrara $\cdot \mathrm{N}$ Barrals. Ben aja selh que $\cdot \mathrm{m}$ noirit, e Dieus!, quar ieu sui aitals, que mil salut mi venon cascun dia de Cataluenha e de Lombardia,
I. Barones, el desleal maldiciente hace convite con mi daño, pues he escogido tal dama en la que el mérito es natural. Y yo la amo de corazón y sin engaño y soy completamente suyo, dondequiera que ella sea mía, porque su valor y su belleza se ostentan de modo que amándola sería honrado un rey, por lo que me considero rico sólo con que se digne decirme sí.

II. Nunca nada me gustó tanto como su perfecto cuerpo leal, en el que están cumplidas todas las buenas cualidades y todo bien sin mal alguno. Y pues en él está todo lo que pertenece a amor, soy bien afortunado, a condición de hallarme a su lado; y si la piedad, por quien aumenta toda buena cualidad, me auxilia con ella, os puedo decir sin ambages que jamás me pudo ayudar tanto en amor.

III. Veo a canto y solaz decaídos que y no se aprecian cortes, los dulces y buenos albergues y la galantería si la dama y el amante no son falsos. Quien con más asiduidad engaña, más consigue. No diré más, pero que ello sea como quiera. Pero me pesa que el primero que antaño empezó a ser falso no fuera extinguido inmediatamente; y hubiera sido justo, pues inició villano ejemplo.

IV. Siento alegrarse mi corazón porque Barral me recuperará. Bien hayan quien me crió y Dios, pues yo soy tal que cada día me llegan saludos de Cataluña y de Lombardía, porque a diario asciende y crece mi mérito,

19 Tomados ambos de M. DE RIQUER, Los trovadores. Historia literaria y textos, 3 vols., Barcelona, 1992, vol. 2, pp. 887-889. 
quar a totz jorns pueja mos pretz e creis; que per un pauc no mor d'enveja·l Reis, quar ab donas fas mon trep e mon joc.

V. Ben es proat et auzit, cum ieu sui pros e cabals, e pus Dieus m'a enriquit, non tanh qu'ieu sia venals.

Cent domnas sai que cascuna $\cdot \mathrm{m}$ volria tener ab se, si aver me podia.

Mas ieu sui selh qu'anc no $\cdot \mathrm{m}$ gaei ni $\cdot \mathrm{m}$ feis ni volgui trop parlar de mi meteis, mas domnas bais e cavaliers derroc.

VI. Mainht bon tornei ai partit pels colps qu'ieu fier tan mortals, qu'en luc non vau qu'om no crit: "So es En Peire Vidals, selh qui manten domnei e drudaria e fa que pros per amor de s'amia; et ama mais batallas e torneis que monjes patz, e sembla 1 malaveis trop sojornar et estar en un loc."

VII. Plus que non pot ses aigua viure 1 peis, non pot esser ses lauzengiers domneis, per qu'amador compron trop car lur joc. [tanto] que por poco muere de envidia el rey, pues con damas hago mis locuras y mis juegos.

V. Probado y reconocido está hasta qué punto yo soy noble y excelente, $y$ pues Dios me ha enriquecido no es preciso que sea venal. Sé de cien damas que cada una de ellas querría tenerme consigo, si pudiera conseguirme. Pero yo soy aquel que jamás se envaneció ni presumió, ni quise hablar demasiado de mí mismo, pero beso a damas y derribo a caballeros.

VI. He dado fin a muchos buenos torneos con los golpes tan mortales con los que acometo, y no puedo ir por ningún sitio sin que se grite: "Éste es Peire Vidal, el que mantiene la galantería y el cortejar y obra como noble por el amor de su amiga; y ama más las batallas y los torneos que el monje la paz, y le parece una enfermedad reposar demasiado y estar [siempre] en el mismo sitio."

VII. Más que sin agua no puede vivir el pez, no puede existir galantería sin maldicientes; por ello los enamorados compran su juego demasiado caro.

Es una cansó a base de coblas unissonans dissolutas con tornada, de nueve bordós o versos cada una más tres la tornada. El interés no obstante queremos centrarlo especialmente en la naturaleza de la melodía que, como es preceptivo, se repite exhaustivamente de cobla a cobla. Peire Vidal se erige como portavoz de un precepto moral: denunciar el daño que hace a los amantes y a su secreto la acción de las malas lenguas. Por supuesto que, en ello, no pierde ocasión para cantar las cualidades de su amada y las bravatas de un ego, marca de este trovador, henchido de sarcasmo y comicidad hacia sí mismo; figuras retóricas como la hipérbole (por ejemplo en "mil salut mi venon cascun dia"), la interpretatio ("mon trep e mon joc") o la anáfora (con la repetición de "que" y "quar" en los comienzos de línea de la cobla IV) refuerzan esta circunstancia. En tanto que portavoz, es muy llamativo que los cuatro primeros bordós, distinguidos por un cómputo menor de sílabas, compartan una misma melodía prácticamente cantilada, a la manera del pregón, el cual, sea dicho, va dirigido a los notables de la corte ("Baron"). Los siguientes cuatro bordós de cada cobla se 
organizan dos a dos según las rimas; así también en cuanto a sus melodías: doble cursus. Esto emparenta inmediatamente la composición con el esquema constructivo de la estampida, sobre todo si sumamos la cantilación de los cuatro primeros bordós, poniendo de relieve quizá la insinuación del juego que -como las justas y torneos en los que Peire se considera un héroe- es el amor. El último bordó supone un giro de ruptura en este sentido, quedando "suelto" con una melodía diferente, del mismo modo que lo hace con la rima; al cabo, si es puro y afinado (fin'amor), el amor es un juego, en efecto, pero demasiado serio y que se compra muy caro.

Sentada esta perspectiva general de la estructura melódica de la cobla, es necesario matizar que existen niveles más profundos de análisis motívico entre cada una de estas cuatro melodías (a saber, la cantilación de los cuatro primeros bordós, la melodía de los bordós cinco y seis, la de los bordós siete y ocho, y la del nueve). Niveles más profundos de análisis que implican, inevitablemente, niveles más amplios de semanticidad, tanto melódica como poética o, mejor, melódico-poética. No vamos a entrar mucho más allá en ellos aquí. Lo que sí es verdaderamente reseñable en aras de nuestra exposición es la denuncia más o menos encubierta de la envidia del rey.

Pero ¿a qué rey se refiere? ¿Por qué? Sin duda, se trata de Alfonso II de Aragón que, tras enemistarse Peire con Raimon V de Toulouse en 1185, acogió a nuestro trovador en su corte, hecho que podría ayudar a datar más exactamente esta cansó entre esta fecha y 1187 (o 1188), momento en el que vuelve a la corte tolosana tras haber pasado también, por ejemplo, por la corte de Alfonso IX de León y haber hecho una peregrinación a Tierra Santa. ${ }^{20}$ Alfonso II, apodado "el Casto", fue notable por sus correrías amorosas e, ironías de los apelativos, no sorprende que Peire, en un plano real o simplemente poético, lo utilice como medida elevada del amor por su amiga. De este modo, distingue los juegos y locuras amorosas del refinamiento y unicidad de la fin'amor: con una amiga así se sentiría honrado un rey.

Envidia, maldicientes, secretos, elevación... Son todos factores que vienen a dejar dos cosas claras. Por encima de todo, que este eros -vestido con los ropajes de la fin'amor- es una "aspiración eterna" embebida de la gestación del deseo: eterna, porque exige eternidad, infinitud, perfección, pero también porque nunca por sí misma se ve cumplida de manera plena. Y, en segunda instancia, que se trata de un sentimiento de corte egoísta ( $\varphi \imath \lambda \alpha v \tau i ́ \alpha$, que diría Platón), ya que sin duda alguna, aunque tiene como confín a la persona amada, nace y muere en el amante. De ahí su doble filo como promesa de felicidad y, por la limitación que se le impone, como posible desapego aniquilador de toda humanidad.

El vuelo de fervor suscitado por eros, entonces, debe ser sometido a una ascesis si quiere alcanzar sus más altas cotas; el cumplimiento de la promesa que lleva inscrita desde el primer instante. ¿Existe alguna manera de que esto así suceda? ¿Debe perderse sin remedio toda renuncia u obstinación en el amor? ¿Es razonable adherirse a este impulso de deseo que respira a la vez alegría y sufrimiento y que se impone al intelecto? Jacopone da Todi, por citar un caso facundo, propone un atisbo de res-

20 E. HOEPFFNER, L'Espagne dans la vie et dans l'oeuvre du troubadour Peire Vidal, Paris, 1946. 
puesta: "a renno celesto, che compie onne festo / che 'l core ha bramato" 21 [En el reino celeste, que cumple toda fiesta / que el corazón ha deseado]. Es en síntesis a lo que llegaron, verbi gratia, San Bernardo de Clairvaux ${ }^{22}$ o Ricardo de Saint-Victor, ${ }^{23}$ es decir, lo que podría llamarse la doctrina del "amor puro" o remonte desde el amor humano/carnal -pues nacemos en la carne- hasta la divinización del amor en el Espíritu Santo.

Vale la pena en este momento dar un salto del amor, ya sea fervor, a la piedad. Porque en el vórtice de esta virtud, bien se hallan las aguas destrenzadas del hontanar mismo del amor. Desde un punto de vista teológico, el fin de la creación, la unión de lo humano y lo divino, una nueva modalidad de existencia, la plenitud última de la naturaleza humana, se dan en el sobrepujamiento de la relación trinitaria, instalado en el amor. La comunión amorosa de las tres personas trinitarias, tal como la han transmitido por ejemplo los Capadocios, se revela en su actuar, que coincide con el

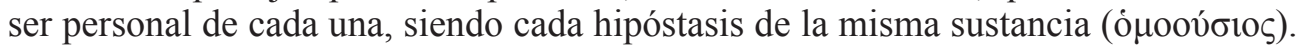
Dicho de otro modo, tenemos que es precisamente lo característico y distintivo de cada una de las personas (es decir, lo que a simple vista las separaría) lo que establece su vínculo en el amor con las otras dos. Así, es peculiar del Espíritu Santo ser conocido con el Hijo y proceder del Padre, al igual que es peculiar del Hijo ser engendrado por el Padre y manifestar el Espíritu Santo. La clave se halla en que la unidad de Dios abarca la unidad de querer y de actuar: una única voluntad. Como en un venero, la potencia trinitaria brota del Padre, que actúa por medio del Hijo y realiza la gracia en la fuerza del Espíritu; pero al margen de cualquier tipo de subordinación aparente, puede decirse que ninguno de sus efectos es atribuible solamente a una u otra persona. De la misma manera que hay un solo movimiento de la voluntad, hay una sola y misma vida, que el Padre produce, el Hijo dispone y que depende del querer del Espíritu. "Sólo el amor es digno de fe", ${ }^{24}$ diría Hans Urs von Balthasar, reduciendo en sus consideraciones este actuar trinitario a la máxima síntesis.

La liturgia misma es un acto de amor, de este amor, y en su sístole y diástole diaria las manifestaciones de éste se multiplican en forma de ejemplos o, lo que es lo mismo, de cantos. Una representación cristalina podemos encontrarla en Cunctipotens genitor Deus, un Kyrie con texto latino, muy relacionado -en abstracto, al me-

21 JACOPONE DA TODI (JACOPO BENEDETTI), Laudi Trattato e Detti, F. AGENO (ed.), Florencia, 1953, Lauda LXIV, vv. 73-74, p. 264.

22 Es representativo el siguiente aserto: "Vultis ergo a me audire quare et quo modo diligendus sit Deus. Et ego: Causa diligendi Deum, Deus est; modus, sine modo diligere" [Quieres entonces oír de mí por qué y cómo debería ser amado Dios. He aquí mi respuesta: la causa de amar a Dios es Dios mismo; la manera, amarle sin medida], BERNARDO DE CLAIRVAUX, De diligendo Deo, I, 1. J.P. MIGNE (ed.), Patrologiae cursus completus. Series latina, Paris, 1844-1864, vol. 182, col. 974A.

23 Valga la afirmación: "In coelestibus itaque desideriis quanto affectus est major, quanto gradus superior, tanto utique melior atque pretiosior. O quam pretiosus primus ille dilectionis gradus in Dei amore, quando est insuperabilis!' [Así que en los deseos celestes cuánto mayor es el afecto: cuanto más alto es el grado (del amor) tanto en verdad mejor y más precioso. ¡Oh, cuán precioso ese primer grado del amor en el amor de Dios, cuando es insuperable!], RICARDO DE SAINT-VICTOR, De quatuor gradibus violentae caritatis, 20. J.P. MIGNE (ed.), op. cit., vol. 196, col. 1214D.

24 H.U. VON BALTHASAR, Sólo el amor es digno de fe, A. CODOVILLA PÉREZ (trad.), Salamanca, 2004. 
nos- con el concepto de tropo, ${ }^{25}$ y que presentamos aquí en la versión polifónica del Códice Calixtino de Santiago de Compostela (Ejemplo 2). En cualquier caso se trata de un caso de "canción litúrgica", concepto que empleamos en oposición a aquellos sectores del repertorio litúrgico de carácter oficial, frecuentemente de sustrato bíblico y de carácter universal, es decir, comunes a toda la iglesia romana y no más particulares de tal o cual centro.

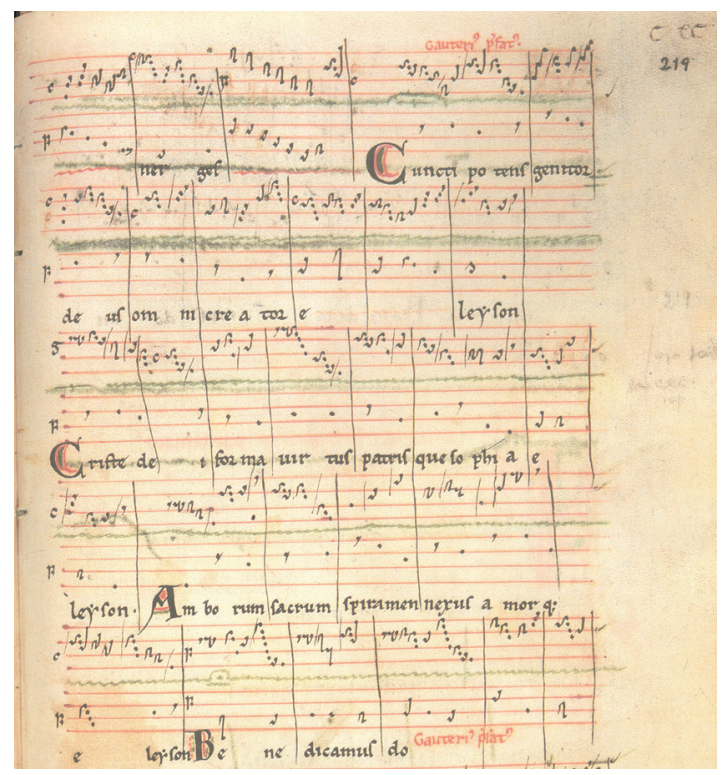

Fig. 2. Cunctipotens gentor Deus. Santiago de Compostela, Bibl. Cap., Cod. Calixtinus, f. 219 r (s. XII med).

Ejemplo 2. Texto y traducción de Cunctipotens genitor Deus

A. Cunctipotens genitor Deus, omni creator, eleison

Dios, Padre todopoderoso, creador de todas las cosas, ten piedad.

B. Christe Dei forma virtus Patrisque sophia, eleison

Oh Cristo, imagen de Dios, virtud y sabiduría del Padre, ten piedad.

C. Amborum sacrum spiramen nexus amorque, eleison

Oh Espíritu Santo, la unión y el amor de ambos, ten piedad.

25 Para una discusión sobre las diferencias entre ambos conceptos véase A. TELLO RUIZ-PÉREZ, Transferencias del canto medieval. Los tropos del Ordinarium Missae en los manuscritos españoles, 2 vols., Madrid, 2008, vol. 1, pp. 157-160 [http://eprints.ucm.es/7758/]; y Transmisión del canto litúrgico en la Edad Media. Los tropos del Ordinarium Missae en España, 2 vols., Saarbrücken (Alemania), 2011, vol. 1, pp. 162181. 
En el Kyrie Cunctipotens genitor Deus, cada elemento o frase caracteriza a una de las personas de la Trinidad: el poder creador del Padre, el Hijo como Logos eterno, y el soplo sacro de amor del Espíritu Santo. Ahora bien, distinción no es sinónimo de oposición y, como decíamos, lo que en apariencia sería una separación, en virtud de una misma voluntad en el actuar, es justo lo que las vincula en comunión. Además, no lo olvidemos, las tres hipóstasis comparten una misma naturaleza. Pues bien, todo ello está representado en este canto a un nivel estrictamente musical. Una pequeña célula melódica del tenor (la voz inferior), es decir, el que sostiene, sirve en una dimensión microestructural para conformar por variación las tres frases que, de otra manera, en apariencia externa, parecerían ser completamente distintas las unas de las otras: misma naturaleza. Y ahí lo tenemos: el texto caracteriza el ser personal de cada persona, lo que las distingue; la música, su misma sustancia en la unidad del amor. Se trata, en definitiva, de una manifestación translúcida de aquel "amor puro", en tanto que cumplimiento del eros, al que nos referíamos antes.

Situados los dos extremos, es decir, el de la promesa del eros y el del amor supremo de la Trinidad, cabría volver sobre algunas de las cuestiones que antes nos formulábamos y que ahora condensamos en una sola: ¿existe puente o vado que permita el tránsito de salvación de uno a otro? Para tratar de dar con un indicio de respuesta conviene que retomemos la cita del Cantar de los Cantares.

En efecto, agapé en vez de eros para expresar el deseo del esposo y la amada. Como decíamos arriba, ello encierra toda una cosmovisión, un cambio de rumbo del "hacia mí" al "hacia ti" que, asimismo, solicita el cotejo electivo y constante de la libertad. Desde el magisterio así lo explica Benedicto XVI en la primera encíclica de su pontificado:

En este contexto, es muy instructivo que a lo largo del libro [el Cantar de los Cantares] se encuentren dos términos diferentes para indicar el "amor". Primero, la palabra "dodim", un plural que expresa el amor todavía inseguro, en un estadio de búsqueda indeterminada. Esta palabra es reemplazada después por el término "ahabá", que la traducción griega del Antiguo Testamento denomina, con un vocablo de fonética similar, "agapé", el cual, como hemos visto, se convirtió en la expresión característica para la concepción bíblica del amor. En oposición al amor indeterminado y aún en búsqueda, este vocablo expresa la experiencia del amor que ahora ha llegado a ser verdaderamente descubrimiento del otro, superando el carácter egoísta que predominaba claramente en la fase anterior. Ahora el amor es ocuparse del otro y preocuparse por el otro. Ya no se busca a sí mismo, sumirse en la embriaguez de la felicidad, sino que ansía más bien el bien del amado: se convierte en renuncia, está dispuesto al sacrificio, más aún, lo busca. ${ }^{26}$

Claro, este testimonio encierra tras de sí todo el tesoro de la tradición en un cofre forjado con piedras preciosas desde época patrística. Por citar sólo un par de casos característicos, encontramos a Orígenes comentando sobre el Cantar de los Cantares:

26 BENEDICTO XVI, Deus caritas est. Introducción y comentario de Angelo Scola, Vaticano (trad.) y Antonio Ciudad (trad. para la introducción y comentario), Madrid, 2006, n. 6, p. 34. 
Igitur si haec ita se habent, sicut dicitur aliquis carnalis amor, quem et cupidinem appellarunt poetae, secundum quem qui amat, in carne seminat; ita est et quidam spiritalis amor, secundum quem ille interior homo amans in spiritu seminat. Et ut evidentius dicam, si quis est qui portat adhuc imaginem terreni secundum exteriorem hominem, agitur cupidine et amore terreno. Qui vero portat imaginem coelestis secundum interiorem hominem, agitur cupidine et amore coelesti. Amore autem et cupidine coelesti agitur anima cum perspecta pulchritudine et decore verbi Dei, speciem ejus adamaverit, et ex ipso telum quoddam et vulnus amoris acceperit. ${ }^{27}$

[Entonces, si esto es así, de la misma manera que hay un amor llamado carnal, que los poetas llamaron Eros, y quien ama según él siembra en la carne, así también existe un amor espiritual, y el hombre interior, al amar según él, siembra en el espíritu. Y por decirlo con mayor claridad, si aún hay alguien portador de la imagen del hombre terreno según el hombre exterior, a este lo mueven el deseo y el amor terrenos; en cambio, al portador de la imagen del hombre celeste según el hombre interior, lo mueven el deseo y el amor celestes. Ahora bien, el alma es movida por el amor y deseo celestes cuando, examinadas a fondo la belleza y la gloria del Verbo de Dios, se enamora de su aspecto y recibe de él como una saeta y una herida de amor]. ${ }^{28}$

O, ya en pleno s. XII, a Elredo de Rievaulx, que concibió su vida entera como una schola caritatis, diciendo:

Haec simul omnia in charitate, et nonnisi in charitate simul omnia; ac perinde in illa vera tranquillitas, vera suavitas, quia ipsa est jugum Domini, quam si, Domino invitante, tulerimus, inveniemus requiem animabus nostris, quia jugum Domini suave est, et onus leve. Denique charitas patiens est, benigna est; non aemulatur, non agit perperam, non inflatur, non est ambitiosa, et caetera. Proinde caeterae virtutes sunt nobis, aut quasi fesso vehiculum, aut quasi viatori viaticum, aut quasi lucerna caligantibus, aut quasi arma pugnantibus: at charitas, quae, licet ut aliae virtutes sint, sit oportet in omnibus, specialius tamen ipsa et requies fatigato, et viatori mansio, et plena lux pervenienti, et perfecta corona victori. ${ }^{29}$

[Todo esto se da en la caridad, y no se encuentra sino en la caridad. Y de la misma manera, en ella, está la verdadera tranquilidad, la verdadera dulzura, porque ella es el yugo del Señor; y si, siguiendo su invitación, la cargamos, hallaremos descanso para nuestras almas, ya que dulce es el yugo del Señor, y leve su carga. Al cabo, la caridad es paciente, es bondadosa; no es envidiosa, no obra maliciosamente, no se jacta, no es ambiciosa, etc. Todas las demás virtudes son para nosotros como un vehículo para el cansado, o como un viático para el caminante, o como una lámpara para los que van a tientas, o como un arma para los que combaten; mas la caridad, aunque deba encontrarse en el resto de las virtudes para que éstas lo sean, es no obstante especial en sí

27 ORÍGENES, In Canticum Canticorum Prologus. Interprete Rufino, J.P. MIGNE (ed.), Patrologiae cursus completus. Series graeca, Paris, 1857-1866, vol. 13, cols. 67A-B. Como buena parte de la producción original de Orígenes, este comentario al Cantar de los Cantares nos ha llegado únicamente a través de la traducción latina de Rufino de Aquileia en el s. V.

28 ORÍGENES, Comentario al Cantar de los Cantares, A. VELASCO DELGADO (trad.), Madrid, 2007, p. 40 .

29 E. DE RIEVAULX, Speculum Charitatis, cap. 31. J.P. MIGNE (ed.), op. cit., 1844-1864, vol. 195, cols. 535B-C. 
misma: reposo para el fatigado, posada para el caminante, plena luz para el que llega y corona perfecta para el vencedor].

Incluso muchos pensadores contemporáneos como Gilson no han podido dejar de constatar este hecho:

El amor humano, sean cuales sean sus ignorancias, sus cegueras y aun sus extravíos, no es más que una participación finita del amor que Dios tiene por sí mismo. La desgracia del hombre es que puede equivocarse de objeto, y padecer por ello, aun sin saber que se equivoca; sin embargo, hasta en los más bajos placeres, hasta en el agotamiento de la voluptuosidad, todavía busca a Dios; aun más: por lo positivo de su acto y lo que aún puede tener de análogo con el amor verdadero, busca a Dios mismo en él, para él.

De modo que, como era de esperar, por lo demás, el fin del amor humano es también su causa. ${ }^{30}$

Lo determinante es que el agapé no elimina al eros, sino que lo rescata; es más, se apoya en él, pues es el deseo. A través de este eros transfigurado que se torna en agapé, es posible remontar la dificultad hacia la concepción del modelo supremo de correlación entre hombre y mujer, entre amante y amada. Todo cambia porque todo necesita de la libertad; nada aparece como imperativo innegable al intelecto, y se requiere el ejercicio activo de la adhesión de la voluntad en un acto completo de dádiva. Atrás quedan los titubeos hondos o superficiales que orbitaban alrededor del amante, ahora sólo importa el bien de la amada: la felicidad como cumplimiento del deseo depende de ello. Santo Tomás de Aquino lo compendia del siguiente modo: "Unde etiam et in hominibus vita uniuscuiusque hominis videtur esse id in quo maxime delectatur, et cui maxime intendit" ${ }^{31}$ [De manera que también en los hombres la vida de cada uno parece ser aquello en lo que más se deleita y en lo que mayor empeño pone]. El affectus, concepto al que en realidad se está refiriendo, sólo alcanza su efecto en virtud de la selección, de la preferencia por un tú, de un amor que deviene en abandono oblativo. Sólo entonces aparece el esfuerzo en tanto que abnegación en favor de un bien mayor, donde ya no se produzca una afirmación del objeto amado sujeta al gusto propio, al impulso de posesión y moldeado ad libitum de la amada por el capricho doblegador del amante.

La secuencia polifónica Maria Virgo virginum del Códice de Las Huelgas será nuestro último ejemplo, por suponer y proponer a María como modelo y camino de relación directa entre el sobrepujamiento amoroso trinitario y la aspiración del deseo humano (Ejemplo 3). El s. XII ya lo tuvo claro y, desde entonces, la Virgen no deja de aparecer constantemente -en ocasiones de forma literal-en racimos interminables de advocaciones e incluso como objeto directo de servicio amoroso; ${ }^{32}$ valga citar como

30 É. GILSON, El espíritu de la Filosofía Medieval, R. ANAYA (trad.), Madrid, 2004, p. 264.

31 SANTO TOMÁS DE AQUINO, Summa Theologiae, cura et studio Instituti Studiorum Medievalium Ottaviensis ad textum S. Pii Pp. Viussu confectum recognita, Ottawa, 1953, II-II, q. 179, a. 1, vol. 3, p. 954.

32 Véanse, por ejemplo, L.M. HERRÁN, "Sentido caballeresco y devoción mariana", Estudios Marianos, 33 (1969), pp. 153-242; y "El servicio de amor en la devoción medieval a Nuestra Señora", Estudios Marianos, 36 (1972), pp. 167-193. 
ejemplos los Milagros de Nuestra Señora de Gonzalo de Berceo, el Liber Mariae de Juan Gil de Zamora, cómo no, las Cantigas de Santa María de Alfonso X, y tantas y tantas otras obras, mayores y menores, que asiéndose a su figura la sitúan como centro de gravedad. Ella es el fundamento, la puerta, el refugio; el amor sin mácula que no traiciona, el palacio de la Trinidad, la posada, la fuente, la luz. Puede decirse que el sentido unitario de la vida del hombre medieval encuentra en María la manifestación más fehaciente del agapé y, por ende, la manera de reconciliar el amor como promesa y aquél como cumplimiento.

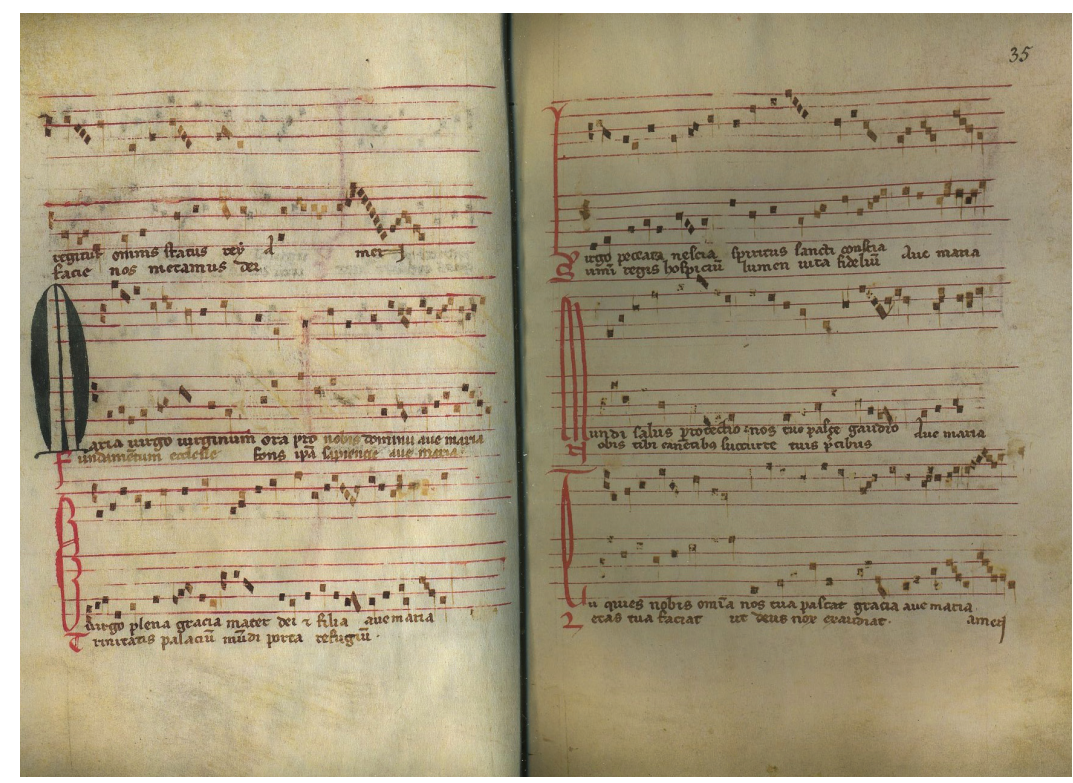

Fig. 3. Maria Virgo virginum. Santa María de Las Huelgas, Bibl. Monast., ff. 34v-35r (s. XIII ex / XIV).

Ejemplo 3. Texto y traducción de Maria Virgo virginum

1a. Maria Virgo virginum ora pro nobis Dominum Ave Maria

1b. Fundamentum ecclesiae fons ipsa sapientiae Ave Maria

2a. O Virgo plena gratia mater Dei et filia

Ave Maria 1a. María, Virgen de vírgenes, ruega por nosotros al Señor. Ave María.

1b. Fundamento de la iglesia, fuente misma de la sabiduría. Ave María.

2a. ¡Oh Virgen, llena de gracia!, madre de Dios e hija.

Ave María. 
2b. Trinitatis palatium mundi porta refugium Ave Maria

3a. Virgo peccati nescia Sancti Spiritus regia Ave Maria

3b. Summi regis hospitium lumen vita fidelium Ave Maria

4a. Mundi salus protectio nos tuo pasce gaudio Ave Maria

4b. Nobis tibi canentibus succurre tuis precibus Ave Maria

5a. Tu que es nobis omnia nos tua pascat gratia

Ave Maria

5b. Gratia tua faciat ut Deus nos exaudiat Ave Maria Amen 2b. Palacio de la Trinidad, puerta del mundo, refugio. Ave María.

3a. Virgen ignara del pecado, pórtico del Espíritu Santo. Ave María.

4a. Hospicio del sumo rey, luz, vida de los fieles.

Ave María.

4a. Salvación del mundo, protección, sosténnos en tu alegría.

Ave María.

4b. A los que te cantamos, socórrenos con tus oraciones.

Ave María.

5a. Tú, que lo eres todo para nosotros, manténnos con tu gracia.

Ave María.

5b. Que tu gracia logre que Dios nos escuche. Ave María. Amén.

Esta composición con el esquema típico de la secuencia -a saber, el doble cursus-, más un refrán -algo no tan habitual en esta categoría de canción litúrgica- con la jaculatoria "Ave María" tras cada hemistiquio de pareado, da cuenta en efecto de que María es vista como el puente, como brandal seguro por el cual el eros se hace agapé. Se trata de un canto al summum bonum de todos y para todos -Nuestra Señora-, una

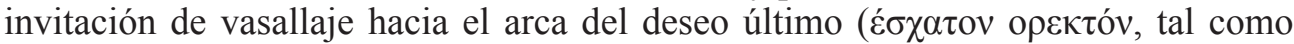
lo define por ejemplo San Basilio de Cesarea) con el ánimo de mostrar sus virtudes sensibles que - dado que en su seno el infinito se hizo finito- enseñen el camino de perfeccionamiento y degustación en pos de la felicidad y de la comprensión de la realidad natural y del empíreo. Reconocer esa alta presencia es alabarla del mejor modo posible, con fervor, con piedad; máxima ésta, por lo demás, muy arraigada también entre los cantores corteses y que entra en concomitancia con otra no menos importante: la calidad del amor se equipara a la calidad del canto. ${ }^{33}$

33 Sirvan como observación de este hecho afirmaciones como: "The greater the devotion of the love, the greater, supposedly, the mastery of the poetic art", M.J. VANLENCY, In Praise of Love: An Introduction to the Love-Poetry of the Renaissance, Nueva York, 1982, p. 108; o "Love inspires the poet both to improve his moral worth and to compose fine songs", L.M. PATERSON, Troubadours and Eloquence, Oxford, 1975, p. 189. 
Precisamente ésta puede ser una buena conclusión a estas breves consideraciones: que el amor se equipara al canto. De este modo, recíprocamente, el conocimiento de uno es tener noticia del otro, de la causa de su impulso creativo, de su transmisión, de su función y razón de ser, de su naturaleza. La tipología del amor, pues, condiciona la manera del canto, y cualquier género de comprensión que quiera tenerse de la música en los reinos hispanos medievales pasa por el filtro de esta realidad inalienable. Aquí, con premura, hemos mostrado sólo unas notas características sobre ello en base a unos pocos ejemplos particulares; sin embargo, fijar la mirada en el espíritu del conjunto - tal era nuestro propósito- puede ser útil para adentrarse en una conciencia, la medieval, en la que pocas cosas se hallaban desconectadas las unas de las otras. ¿Acaso no es más fácil entender los riachuelos desde su horizonte último que es el mar? 